\title{
Ventriculoatrial Conduction in Complete Atrioventricular Block Due to AH Block
}

\author{
Hiromitsu Tanaka, M.D., * Hiroshi Katanazako, M.D., \\ Nobuhiro Uemura, M.D., * Yoshifumi Toyama, M.D.,* \\ Takuya Kanehisa, M.D.,* and Kenzi Amatatsu, M.D.**
}

\section{SUMMARY}

In 2 patients with complete heart block, characteristics of retrograde conduction and the localization of orthograde conduction block were studied. In patient 1, retrograde conduction was demonstrated during both A-V junctional rhythm and ventricular pacing. The sinus and retrograde $P$ waves seemed to utilize and compete for the $A \cdot V$ conduction system. The time from $Q R S$ complexes to retrograde $P$ waves was longer during ventricular pacing than during $\mathrm{A}-\mathrm{V}$ junctional rhythm by approximately 65 to $110 \mathrm{msec}$. 1: 1 ventriculoatrial conduction could be elicited at the ventricular pacing rate between 70 and 100 beats per minute. The time interval between the pacemaker impulse and the retrograde $P$ wave became progressively longer as the pacing rate increased. The V-A conduction showed Wenckebach phenomenon with $5: 4$ conduction ratio at the rate of $110 / \mathrm{min}$, and that with $3: 2$ conduction at $120 / \mathrm{min}$, respectively. The His bundle electrogram demonstrated a complete heart block due to $\mathrm{AH}$ block. In patient 2, electrocardiogram during a Stokes-Adams attack showed complete heart block and an escape rhythm with retrograde $P$ waves. The $Q R S$ complexes of the escape rhythm were normal in configuration and duration, indicating an A-V junctional origin. At the time of His bundle recording, ECG showed 1:1 atrioventricular conduction. Although PA, AH and $\mathrm{HV}$ times were all within normal limits without any intervention, $\mathrm{AH}$ time developed a Wenckebach periodicity in response to atrial pacing rate of 90 beats per minute or higher. Therefore, it was presumed that the complete heart block demonstrated during a StokesAdams attack had been due to $\mathrm{AH}$ block. These studies indicate that a retrograde $\mathrm{V}-\mathrm{A}$ conduction could occur in the presence of orthograde $\mathrm{A}-\mathrm{V}$ block due to AH block. Possible mechanisms of retrograde $\mathrm{V}$-A conduction in the presence of complete orthograde $\mathrm{AH}$ block were discussed, and unidirectional block at the $\mathrm{A}-\mathrm{V}$ junction seemed to be the most probable mechanism operating in our patients.

\footnotetext{
* From the Frist Department of Internal Medicine, Faculty of Medicine, Kagoshima University, Kagoshima, Japan.

** The Second Department of Surgery, Faculty of Medicine, Kagoshima University.

Supported partly by Research Grant from the National Racing Welfare Foundation.

Received for publication August 7, 1973.
} 


\section{Additional Indexing Words:}

$\begin{array}{lrr}\text { Retrograde P wave } & \text { Retrograde conduction time } & \text { Retrograde block } \\ \text { His bundle electrogram } & \text { A-V junctional rhythm } & \text { Ventricular pacing } \\ \text { Stokes-Adams syndrome } & \text { Decremental conduction } & \text { Unidirectional block }\end{array}$

$\mathrm{I}^{\mathrm{T}}$

$T$ is well known that the A-V transmission system is capable of both forward and retrograde conduction. However, occurrence of retrograde conduction in the presence of $\mathrm{A}-\mathrm{V}$ (forward) block may still appear paradoxical. Scherf and Cohen ${ }^{1)}$ reviewed the literature in 1964 and collected 81 reported cases of V-A conduction in A-V block. Retrograde conduction to the atria following escape beats ${ }^{2)-5}$ ) as well as ventricular premature beat ${ }^{6}{ }^{\text {) }}$ has been reported in complete heart block. More recently, retrograde conduction has been observed occasionally during ventricular pacing in patients with complete heart block. ${ }^{7-11)}$ Samet et al ${ }^{103}$ found V-A conduction in 10 out of 15 patients with complete heart block, whereas Goldreyer et al ${ }^{11}$ ) were able to produce $\mathrm{V}$-A conduction in only 1 of 12 patients showing high grade $\mathrm{A}-\mathrm{V}$ block by selecting appropriate rates of ventricular pacing. $\mathrm{We}^{12)}$ have also reported that $\mathrm{V}$-A conduction was elicited by ventricular pacing in 1 of 7 patients with complete $\mathrm{A}-\mathrm{V}$ block. Contraversies as to the mechanism of retrograde conduction in the presence of complete heart block are still unsettled. The site of orthograde A-V conduction block and the conducting tissue through which retrograde impulse proceeds have not been adequately described except in one paper. ${ }^{13)}$ The introduction of His bundle recording in man by Scherlag $e$ al $^{14)}$ allowed us to localize the site of A-V block. If we can determine the localization of orthograde block by His bundle recordings and if we can infer from it the nature of the pathway for retrograde conduction, the mechanism of such unidirectional transmission may be clarified.

The purposes of this paper are (1) to describe the results of studies on the location of the orthograde block and on the characteristics of the retrograde conduction in 2 patients of complete heart block with retrograde conduction, and (2) to discuss, on the basis of these observations, the mechanism of the retrograde $\mathrm{V}$-A conduction observed in these patients.

Patient 1

Case history: An 80-year-old fisherman was admitted on October 26, 1972, to Kagoshima University Hospital because of Stokes-Adams attacks. He had been in good health until 6 days prior to admission when he experienced severe syncopal attacks. ECG taken during an attack showed complete A-V block. Intravenous isoproterenol (Proternol) was effective in accelerating the heart rate and restoring intermittent $A-V$ conduction. Since it proved impossible to wean him off this intravenous therapy, he was referred to our hospital and immediately admitted. On admission, he was drowsy. Pulse rate was $40 / \mathrm{min}$ and irregular; blood pressure 


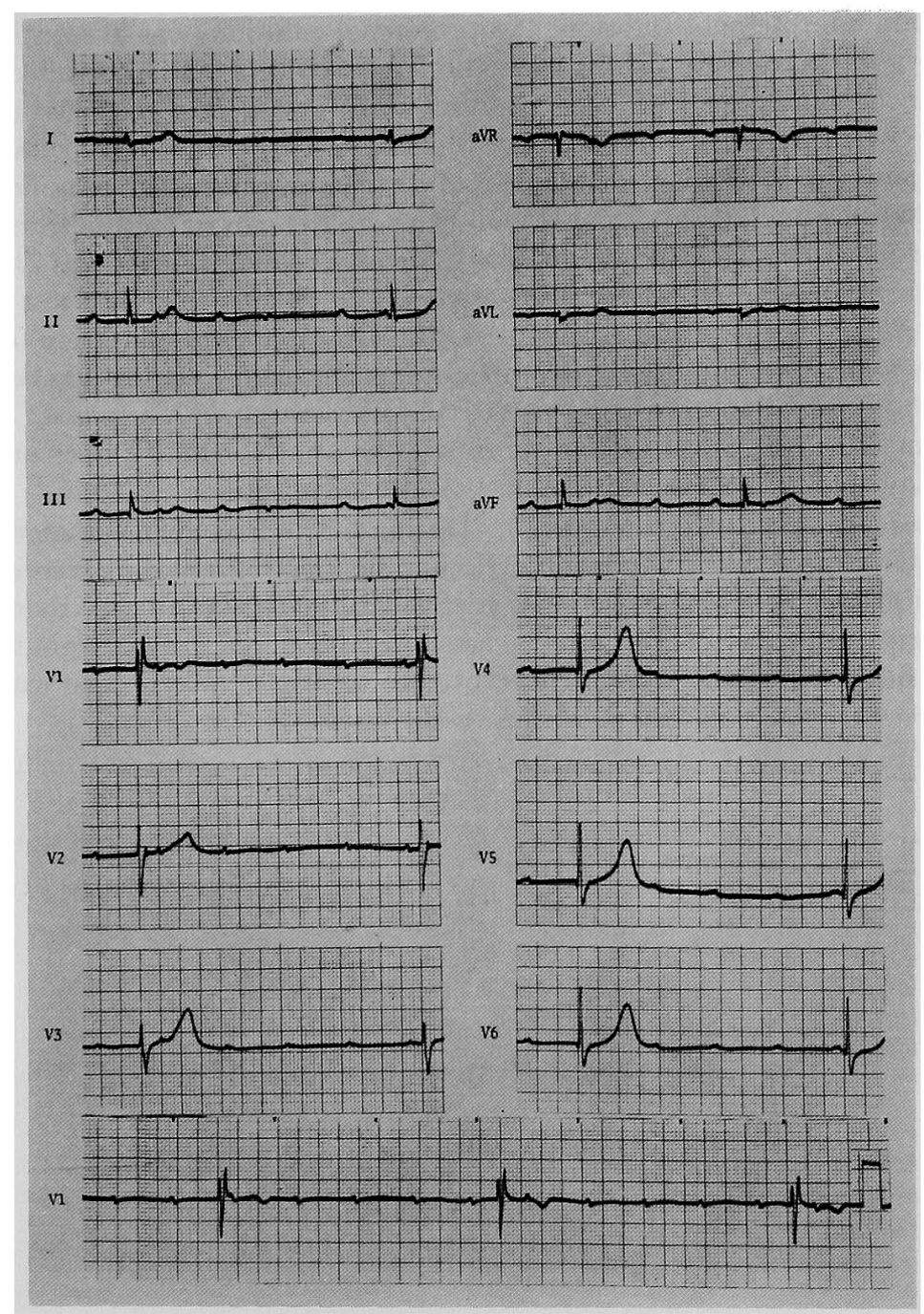

Fig. 1. Patient 1. EGG on admission shows complete A-V block with A-V junctional rhythm. QRS complexes show an incomplete right bundle branch block pattern and measure $0.11 \mathrm{sec}$ in duration. The RR intervals are either $2.6 \mathrm{sec}$ or $1.8 \mathrm{sec}$, suggesting an irregular subsidiary pacemaker activity or presence of 2 pacemakers in the A-V junction probably resulting from isoproterenol infusion. There are occasional atrial premature beats.

was $135 / 60 \mathrm{mmHg}$. The first heart sound was variable in intensity. There was a soft, Grade 1 systolic flow murmur at the base. ECG taken immediately after admission disclosed complete A-V block and left atrial strain (Fig. 1). The QRS complexes showed incomplete RBBB pattern with a duration of 0.11 sec. The rate of the sinus $\mathrm{P}$ wave and that of the escape rhythm were 100 and, 33 or 23 beats per minute, respectively. The RR intervals were 2.6 or $1.8 \mathrm{sec}$, suggesting an irregular pacemaker activity or presence of 2 pacemakers in the A-V junction probably re- 
sulting from isoproterenol infusion. Isoproterenol infusion was discontinued immediately after taking this EGG, then the irregularity of $R R$ intervals disappeared and the RR intervals had been constant until emergency pacemaking. Atrial premature beats were demonstrated occasionally. The chest X-ray showed slight cardiomegaly with a cardiothoracic ratio of 51 per cent and clear lung fields. Laboratory findings included normal urinalysis and CBC, normal serum transaminase, normal serum electrolytes and creatinine. Serum cholesterol level was $210 \mathrm{mg} / 100$ $\mathrm{ml}$. Serologic test for syphilis was negative. The glucose tolerance test showed a normal pattern. Vital capacity was $2,430 \mathrm{ml}$. On the day of admission, a catheter electrode was inserted into the right ventricle and temporary pacing was begun. On the seventh hospital day, a permanent demand pacemaker with a rate set at $70 / \mathrm{min}$ was implanted. The postoperative course was uneventful. ECG taken on eleventh hospital day showed an intermittent $1: 1 \mathrm{~A}-\mathrm{V}$ conduction.

Methods of electrophysiological studies: During the insertion of a catheter electrode for emergency pacing on admission, His bundle electrogram was recorded using the techniques of Scherlag et al. ${ }^{14)}$ Under local anesthesia, an electrode catheter (Castillo tripolar probe, 7F, Elecath Co, Ltd) was introduced into the right saphenous vein and fluoroscopically positioned across the tricuspid valve. The leads of the

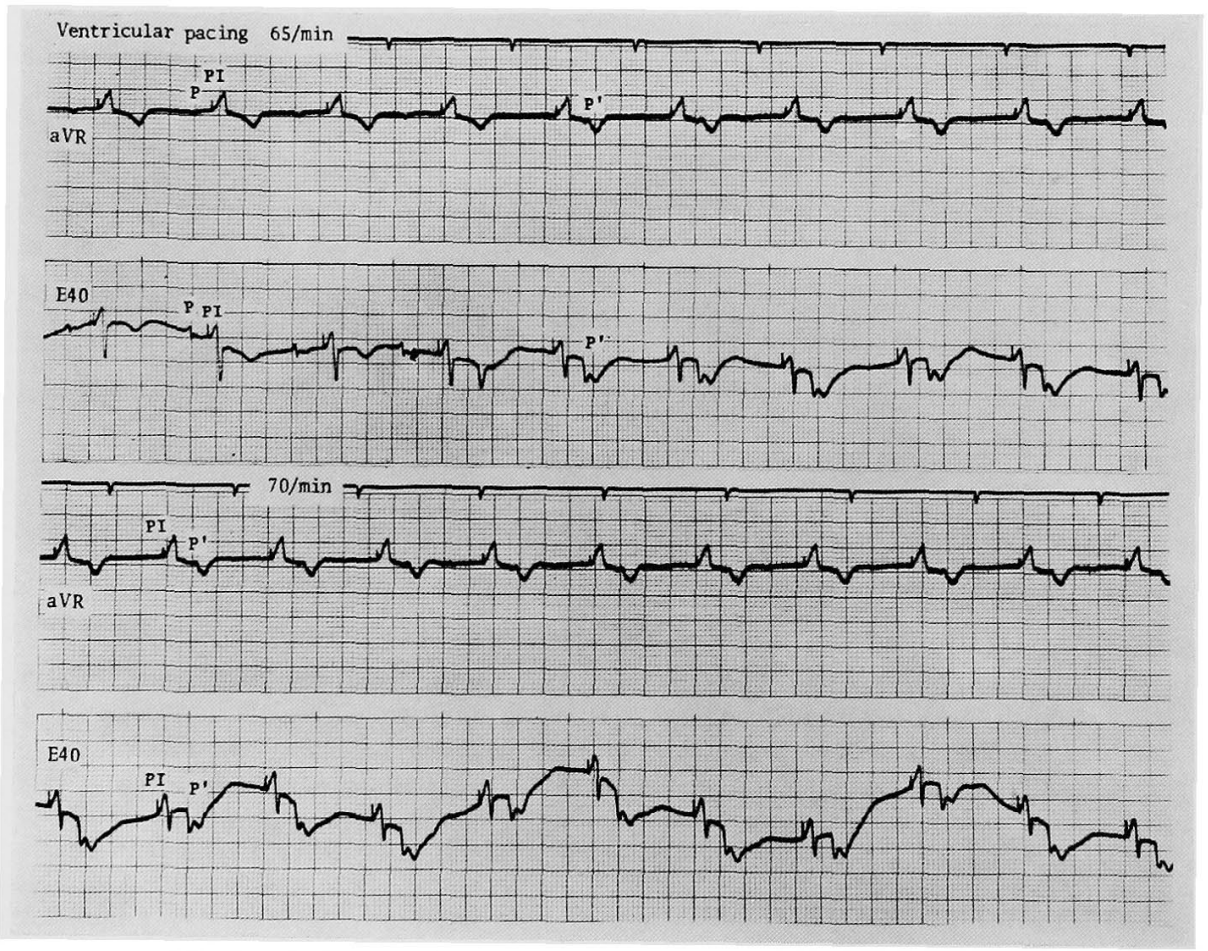

Fig. 2. Patient 1. Upper panel shows ECG (aVR and esophageal leads) during ventricular pacing at $65 / \mathrm{min}$. Retrograde $P$ waves do not follow the first 3 QRS complexes but follow the remaining QRS complexes. Lower panel shows ECG during ventricular pacing at 70/min. 1:1 V-A conduction with a constant PI-P' interval is shown. P: $\mathbf{P}$ wave of sinus origin; $\mathrm{P}^{\prime}$ : retrograde $\mathrm{P}$ wave and $\mathrm{PI}$ : pacemaker impulse. 


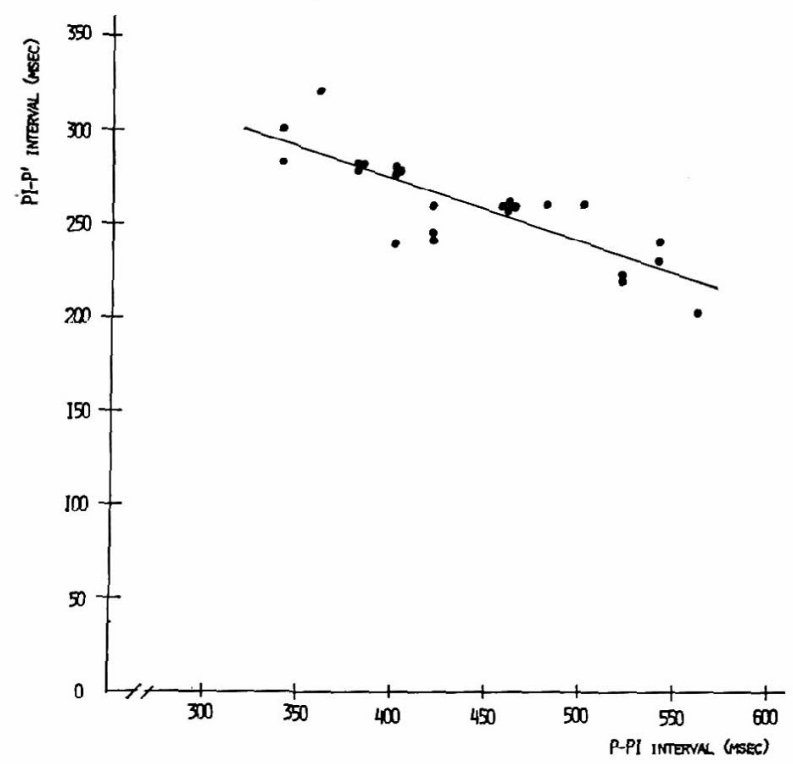

Fig. 3. Patient 1. The relationship between P-PI and PI-P' intervals. The P-PI and PI-P' intervals are related inversely $(\mathrm{Y}=407-0.333 \mathrm{X}, \mathrm{p}<$ 0.001).

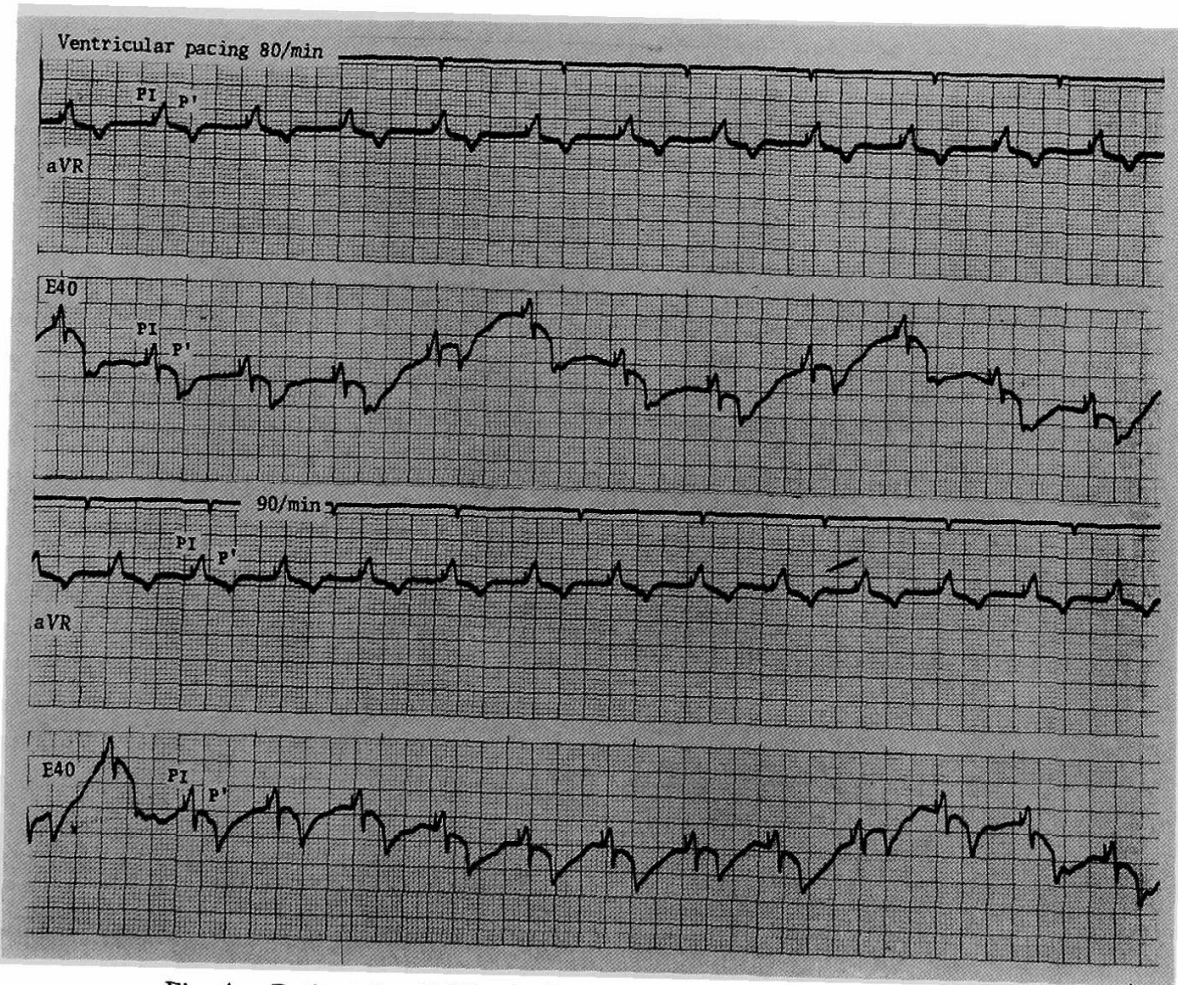

Fig. 4. Patient 1. ECGs during ventricular pacing at $80 / \mathrm{min}$ (upper panel) and 90/min (lower panel) show 1:1 retrograde conduction with respective PI-P' intervals of 0.23 and 0.25 sec. 
catheter were connected to a multipurpose polygraph, Model RM-150 (Nihon Kohden Co, Ltd), with the frequency response set at $1 \mathrm{KHz}$ and the time constant at $0.003 \mathrm{sec}$. The paper speed used was either 50 or $125 \mathrm{~mm} / \mathrm{sec}$. The pacemaker generator used was a demand pacemaker type 5880A (Medtronic Go, Ltd). After His bundle electrogram recordings were obtained and an electrode catheter for emergency pacing was inserted, a unipolar esophageal EGG was recorded by 4 channel electrocardiogragh, Model MC-3 (Nihon Kohden Co, Ltd), together with either 2 of the leads aVR, aVF, II and V1. The rate of ventricular pacing was sequentially increased from 50 to $120 / \mathrm{min}$ in steps of 5 to 10 beats per minute every 10 to $20 \mathrm{sec}$. The patient complained only slight palpitation at pacing rates of $100 / \mathrm{min}$ or greater. No anginal pain was noticed.

The following criteria were used to identify retrograde $\mathrm{P}$ waves: (1) $\mathrm{P}$ waves are positive in aVR and negative in $\mathrm{aVF},{ }^{2)}$ (2) $\mathrm{P}$ wave pattern is different from the sinus $\mathrm{P}$ in esophageal lead, ${ }^{15)}$ and (3) $\mathrm{P}$ waves follow $\mathrm{QRS}$ complexes either at a fixed interval ${ }^{111}$ or with Wenckebach periodicity at individual pacing rates. The following intervals were measured: (1) P-PI: the interval from the preceding sinus $\mathrm{P}$ to a pacemaker impulse, (2) PI- $\mathrm{P}^{\prime}$ : the interval from a pacemaker impulse to the retrograde $\mathrm{P}$ wave, (3) P-R: the interval from the preceding sinus $\mathrm{P}$ to a $\mathrm{QRS}$

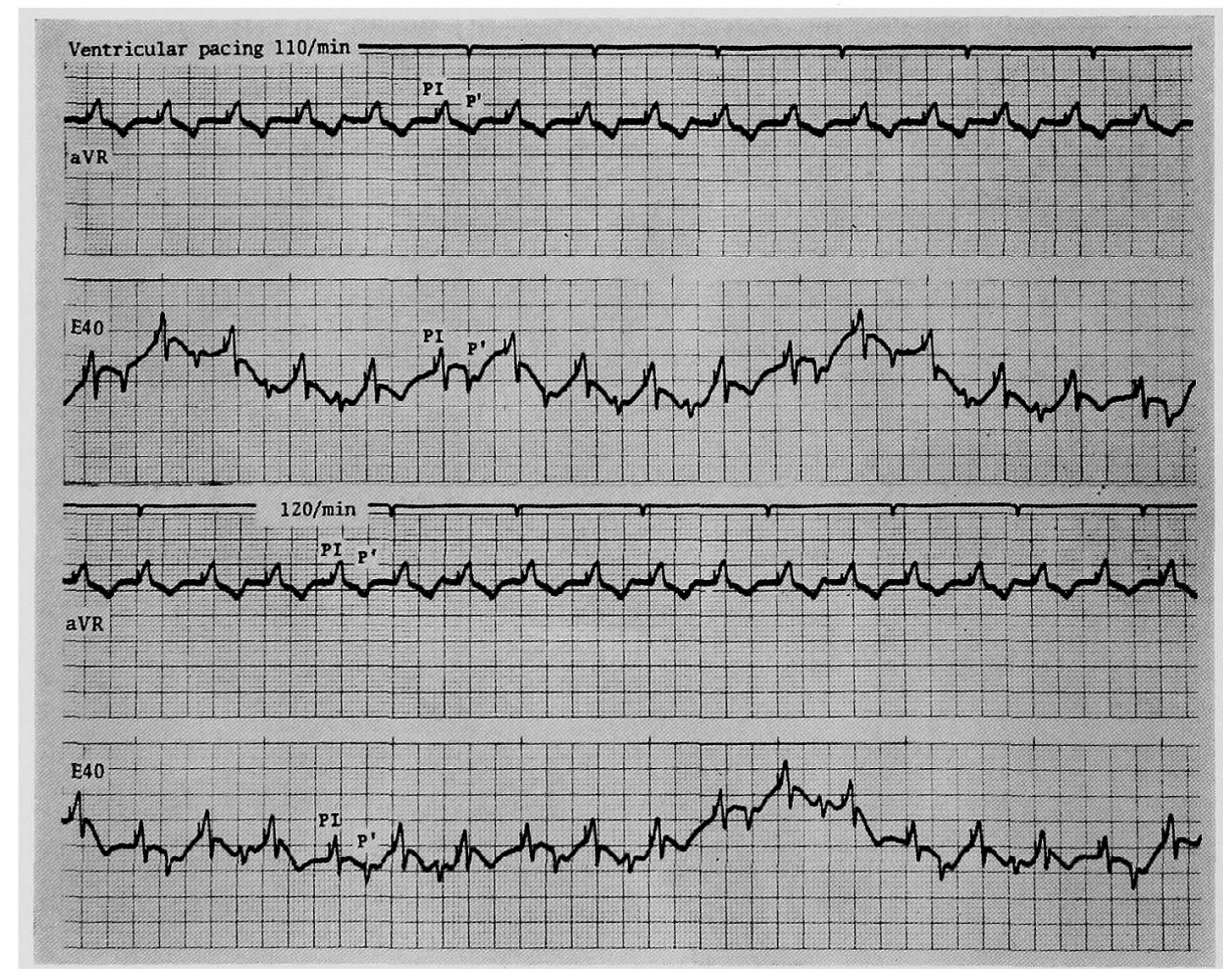

Fig. 5. Patient 1. EGG during ventricular pacing at $110 / \mathrm{min}$ (upper panel) and $120 / \mathrm{min}$ (lower panel). In the upper panel, the PI-P' interval becomes progressively longer until every fifth pacemaker impulse (PI) fails to be conducted (Wenckebach type V-A block with 5:4 V-A conduction). Lower panel shows Wenckeback type V-A block with 3:2 V-A conduction. 
complex during escape rhythm, (4) R-P': the interval from a QRS complex to the retrograde $\mathrm{P}$ wave during escape rhythm, and (5) $\mathrm{PA}, \mathrm{AH}$, and $\mathrm{HV}$ in $\mathrm{His}$ bundle electrogram, according to Narula et al.16)

Results: In the upper panel of Fig. 2, small diphasic $\mathbf{P}$ waves in the esophageal lead and negative $P$ waves in aVR are of sinus origin, whereas large negative $P$ waves in the esophageal lead and small positive $P$ waves in aVR represent retrograde atrial activation. During ventricular pacing at $65 / \mathrm{min}$, retrograde $P$ waves were not seen when P-PI was less than 320 msec but appeared following QRS complexes when P-PI was more than $340 \mathrm{msec}$. The P-PI and PI-P' intervals were related inversely, as shown in Fig. 3. The maximum value of PI-P' interval was $320 \mathrm{msec}$ (P-PI interval was $360 \mathrm{msec}$ ) and the minimum value was $200 \mathrm{msec}$ (P-PI was $560 \mathrm{msec}$ ): At the rate of $70 / \mathrm{min}, 1: 1$ retrograde conduction could be elicited (lower panel of Fig. 2). PI-P' interval was almost constant at $0.225 \mathrm{sec}$. At pacing rates of 80 and 90/min, 1: 1 retrograde conduction was again observed with PI-P' intervals of 0.23 and $0.25 \mathrm{sec}$, respectively (Fig. 4). When the pacing rate was increased to $110 / \mathrm{min}$, retrograde conduction showed a Wenckebach phenomenon. In the upper panel of Fig. 5, the PI-P' interval became progressively longer until every fifth pacemaker impulse (PI) was not conducted to the atria. In the lower panel of the same figure, the PI-P' interval again progressively increased until every third PI failed to be conducted. These relationships between the pacing rate and the PI-P' interval are summarized in Fig. 6. Fig. 7 shows the His bundle electrogram recorded during

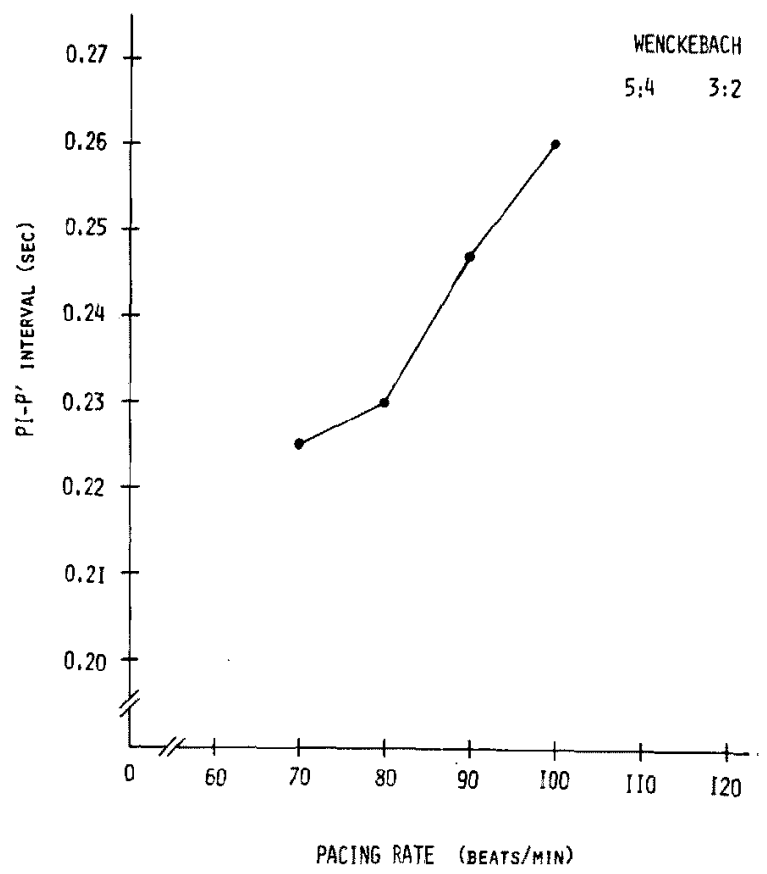

Fig. 6. Patient 1. The relationship between ventricular pacing rate and the PI-P' interval. The PI-P' interval becomes progressively longer at pacing rates between 70 and 100 beats per minute until Wenckebach type V-A block appears at the rate of 110 and $120 / \mathrm{min}$. 


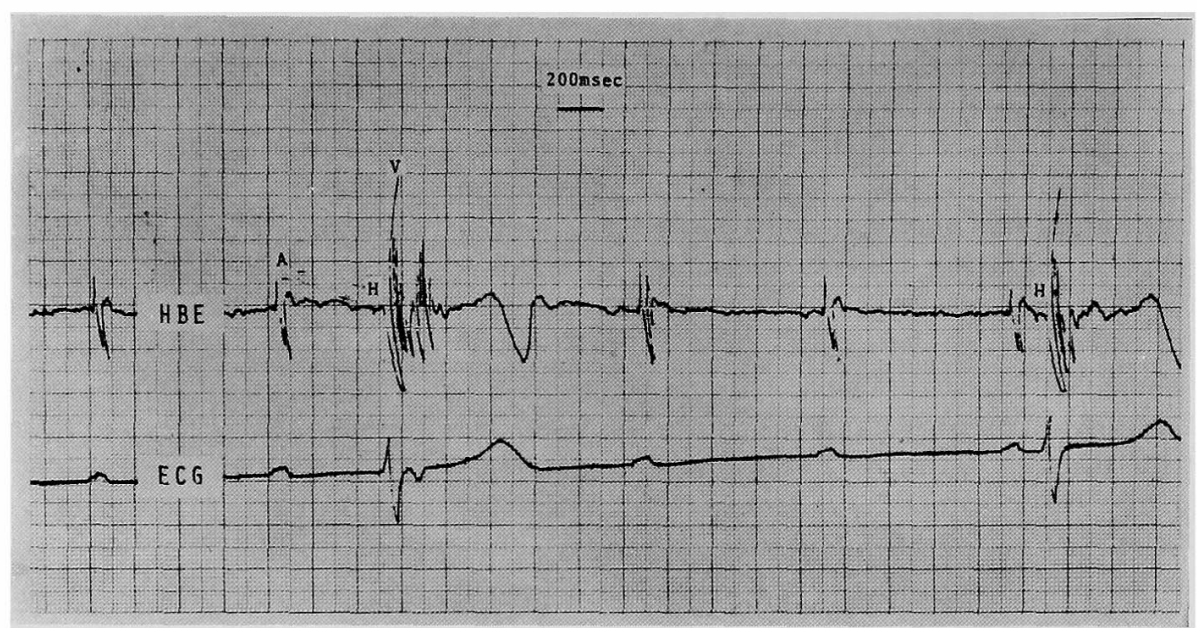

Fig. 7. Patient 1. His bundle electrogram and lead aVF during spontaneous A-V junctional rhythm show a complete heart block due to AH block and the escape rhythm probably originated above the His bundle recording site. The third $\mathrm{P}$ wave shows retrograde atrial depolarization. The $\mathrm{HV}$ interval is $40 \mathrm{msec}$. The QRS complexes measure $110 \mathrm{msec}$ in duration and the major deflection of the QRS is downward, suggesting the association of left anterior hemiblock with A-V junctional escape rhythm. The RR intervals were regular and measured $2,950 \mathrm{msec}$.

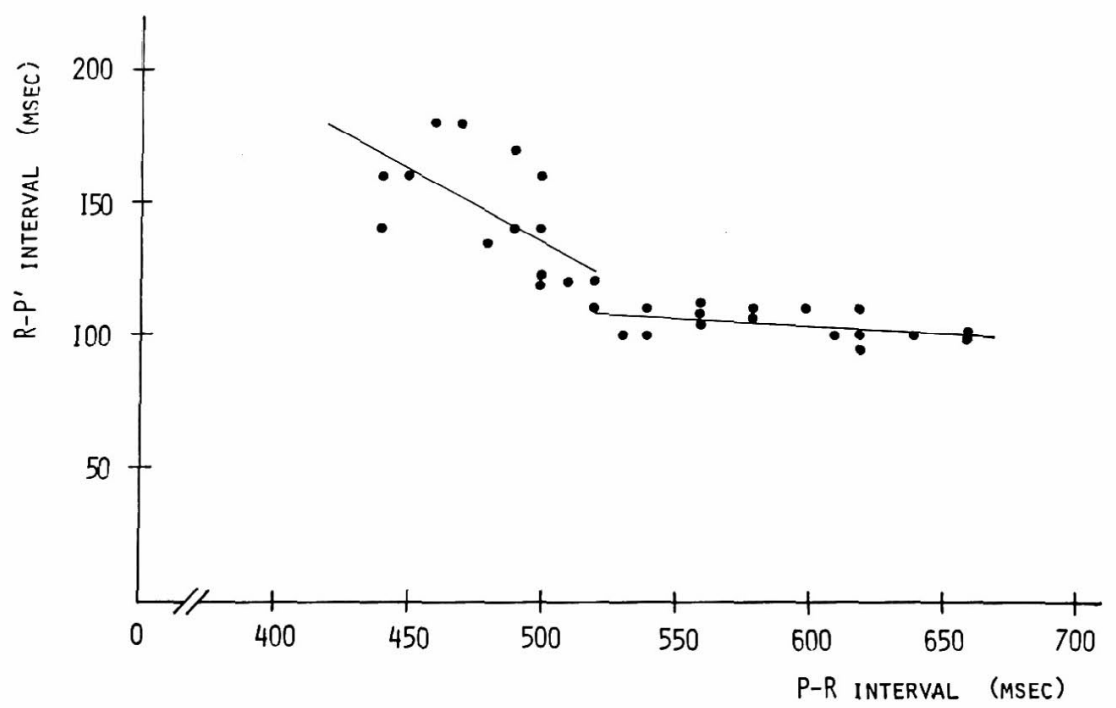

Fig. 8. Patient 1. The relationship between the P-R and R-P' intervals. The $R-P^{\prime}$ interval is inversely related to the $P-R$ interval when the $\mathrm{P}-\mathrm{R}$ intervals are in the range of 440 to $520 \mathrm{msec}(\mathrm{Y}=408-0.546 \mathrm{X}, \mathrm{p}<$ 0.005). The R-P' interval remains almost constant at the $P-R$ intervals between 520 and 670 msec. 
a spontaneous escape rhythm. The A waves are not followed by His potential, whereas the $\mathrm{V}$ waves are always preceded by $\mathrm{H}$ deflections with a constant interval of $40 \mathrm{msec}$. The RR intervals were regular and measured 2,950 msec. Thus the complete heart block in this case was proved to result from $\mathrm{AH}$ block and the escape rhythm probably originated above the His bundle recording site. In this His bundle electrogram, the third $\mathrm{P}$ wave in lead aVF is negative and the corresponding $\mathrm{A}$ wave is different in shape, indicating retrograde conduction from the escape pacemaker. A number of retrograde $\mathrm{P}$ waves were recorded in the His bundle electrogram. Retrograde P waves were not observed when P-R intervals were $300 \mathrm{msec}$ or less and were observed only when P-R intervals were $440 \mathrm{msec}$ or longer. Fig. 8 shows the relationship between the P-R and R-P' intervals. The R- $\mathrm{P}^{\prime}$ interval was inversely related to the $P-R$ interval when the $P-R$ intervals were in the range of 440 to 520 msec. The maximum R-P' interval was $180 \mathrm{msec}$ when the P-R intervals were 460 and $470 \mathrm{msec}$. When the P-R intervals were between 520 and $670 \mathrm{msec}$, the R-P' interval remained almost constant at the range between 95 and $112 \mathrm{msec}$.

\section{Patient 2}

A 70 -year-old barber was admitted because of syncopal attacks. Six months prior to admission, he had several attacks of syncope. He was told that he had a bradycardia and was under medical treatment. However, syncopal attacks persisted, and he was transferred to Kagoshima University Hospital on October 4, 1972. ECG taken on August 28, 1972, revealed a complete A-V block with QRS complexes normal in configuration and duration $(0.09 \mathrm{sec})$, indicating an $\mathrm{A}-\mathrm{V}$ junctional rhythm. In Figs. 9 and 10, narrow, negative $\mathrm{P}$ waves follow the second and third QRS in lead II, and a positive $\mathrm{P}$ wave follows the last $\mathrm{QRS}$ in V1. Since the sinus $\mathrm{P}$ waves were positive in lead II and negative in Vl, the above $\mathrm{P}$ waves were thought to re-

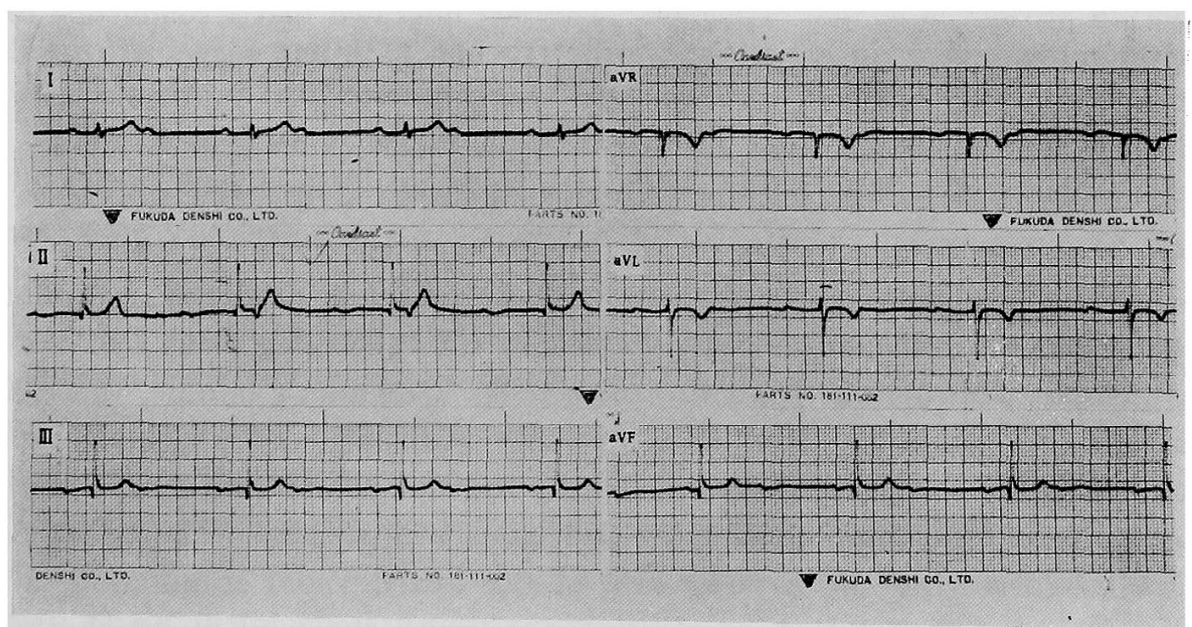

Fig. 9. Patient 2. ECG (extremity leads) taken immediately after a Stokes-Adams attack showing complete heart block and an A-V junctional rhythm. The QRS complexes are normal in configuration and duration $(0.09 \mathrm{sec})$. $P$ waves following the second and third QRS complexes in lead II are retrograde $P\left(P^{\prime}\right)$. The $P-R$ intervals (the interval from the preceding sinus $\mathrm{P}$ to $\mathrm{QRS}$ complex) are $0.20 \mathrm{sec}$. 


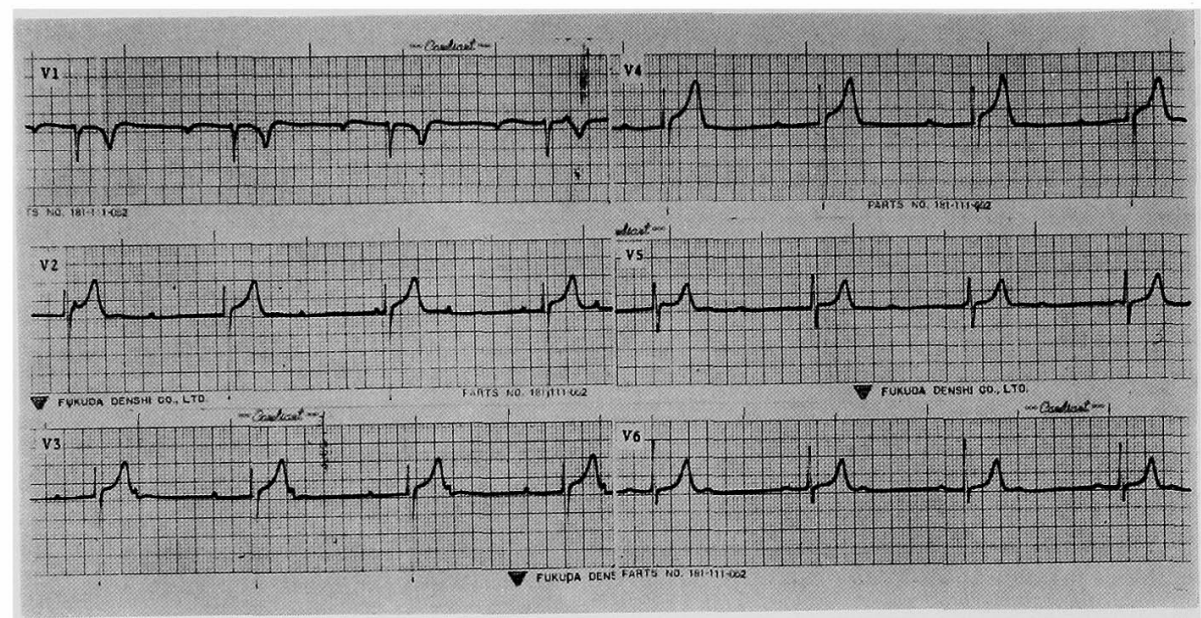

Fig. 10. Patient 2. EGG (precordial leads) showing a retrograde $P$ after the last QRS complex in V1.

present retrograde conduction. The interval from the QRS complexes to the following retrograde $\mathrm{P}\left(\mathrm{R}-\mathrm{P}^{\prime}\right.$ interval) was $0.20 \mathrm{sec}$ and the corresponding intervals from the preceding sinus $\mathrm{P}$ wave to the $\mathrm{QRS}$ ( $\mathrm{P}-\mathrm{R}$ intervals) were $0.62,0.60$ and $0.58 \mathrm{sec}$, respectively. ECG taken on admission revealed a complete heart block and normal QRS similar to the ECG recorded on August 28, 1972 (Figs. 9 and 10). On the third hospital day, when His bundle electrogram was recorded, ECG showed a normal 1: $1 \mathrm{~A}-\mathrm{V}$ conduction. $\mathrm{PA}, \mathrm{AH}$ and $\mathrm{HV}$ intervals were 35,70 and $45 \mathrm{msec}$, respectively. During atrial pacing, Wenckebach type A-V block due to AH block was observed at rates of $90 / \mathrm{min}$ or higher. This fact indicated that a conduction disturbance was present in regions above the His bundle, ${ }^{17)}$ and suggested that the previous periods of complete heart block most likely resulted from an $\mathrm{AH}$ block.

\section{Discussion}

(1) Electrophysiological characteristics of ventriculoatrial conduction: Damato et $a l^{18)}$ studied ventriculoatrial conduction in the intact dog heart by recording bipolar electrograms from the sinus node, Bachman's bundle, the right and left atria, the bundle of His, and the ventricle. They demonstrated that retrograde conduction time exceeded antegrade conduction time, that the zone of retrograde conduction delay and block was in the A-V nodal region, and that increasing the driving rate of the heart, vagal stimulation, and isoproterenol, affected V-A conduction similar to the way in which these maneuvers affected A-V conduction. Goldreyer and Bigger ${ }^{11)}$ studied ventriculoatrial conduction in man utilizing strict criteria for retrograde conduction. V-A conduction time was significantly longer than the A-V conduction time in all but 2 of the 23 patients with normal A-V conduction 
who demonstrated 1:1 V-A response. The V-A effective refractory period was longer than the A-V effective refractory period. Any degrees of $\mathrm{V}-\mathrm{A}$ block could be produced by increasing the ventricular pacing rate or introducing ventricular test stimuli during the relative V-A refractory period. Recently, we $\mathrm{e}^{12)}$ also studied the relationships of ventriculoatrial conduction with atrio-ventricular conduction in man, by serially increasing the rates of atrial or ventricular pacing. In 1 out of 5 patients in whom a $1: 1 \mathrm{~V}$-A conduction was elicited, A-V conduction time was prolonged rapidly as the pacing rate increased, whereas $\mathrm{V}$-A conduction time remained almost constant, and both A-V and V-A conduction showed 1:1 response up to the pacing rate of 120/ min. In the remaining 4 patients, V-A conduction time became progressively longer, in parallel with an increase in the A-V conduction time as the pacing rate increased, until Wenckebach phenomenon or Mobitz type 2 block appeared. In 3 out of these 4 patients, V-A conduction developed such block at pacing rates less than in $\mathrm{A}-\mathrm{V}$ conduction. The pacing rates at which second degree V-A block appeared were 100 beats per minute in 2 patients and $130 / \mathrm{min}$ in another, respectively.

The fact that V-A conduction time in patient 1 prolonged progressively until Wenckebach block appeared at the pacing rate of $110 /$ min was very similar to the characteristics of retrograde V-A conduction demonstrated in man as well as in canine heart.

The bypass tracts observed in pre-excitation syndrome have been reported to show no progressive increase in orthograde ${ }^{19)}$ or retrograde ${ }^{20)}$ conduction time with a progressive increase in the rate of atrial or ventricular pacing.

(2) Localization of the orthograde block and the retrograde conduction: In 1972, Gupta and $\mathrm{Haft}^{13)}$ described a patient with complete heart block and retrograde V-A conduction. His bundle recordings demonstrated that orthograde block occurred beyond the bundle of His and that retrograde conduction proceeded through the A-V node. They concluded that retrograde conduction could occur in complete heart block if the block was beyond the bundle of $\mathrm{His}$ and if the A-V node was intact. They were unable to determine whether the retrograde impulse went around the site of block to the A-V node or through the blocked conduction system distal to the His bundle. It seems to be difficult to exclude the possibility that the unidirectional block existed in the distal His-Purkinje system. ${ }^{211}$

Complete heart block was duc to $\mathrm{AH}$ block in our patient 1 and complete A-V block with retrograde conduction during Stokes-Adams syndrome seen in patient 2 was also presumed to be due to $\mathrm{AH}$ block as evidenced by the fact that $\mathrm{AH}$ interval showed Wenckebach phenomenon in response to 
atrial pacing rate of $90 / \mathrm{min}$. Therefore, 2 patients presented here are examples of retrograde conduction in the presence of complete A-V block due to $\mathrm{AH}$ block, i.e. the site of orthograde $\mathrm{A}-\mathrm{V}$ block is either at the atrial junction with the $A-V$ node, within the $A-V$ node or the uppermost portion of the bundle of His. ${ }^{16)}$

Electrocardiograms showing retrograde $\mathrm{V}$-A conduction in the presence of complete or high degree $A-V$ block and A-V junctional rhythm, which indicate an $\mathrm{A}-\mathrm{V}$ block either due to $\mathrm{AH}$ or $\mathrm{HB}$ block, ${ }^{16}$ ) have been reported by several investigators: 5 out of 25 cases examined by Winternitz and Langendorf;3) Scherf and Cohen (Fig. 83);1) Scherf, Cohen, and Orphanos (Fig. 1). ${ }^{2}$

(3) Retrograde conduction time from the escape rhythm: The PI-P' intervals were longer than R-P' intervals by 65 to $140 \mathrm{msec}$ at respective P-PI and P-R intervals (sce Figs. 3 and 8 ) in patient 1 . This fact clearly indicates that retrograde conduction observed during the escape rhythm was not elicited by direct effects of ventricular depolarization but was elicited by impulses which arose at the pacemaker site located in the A-V junctional tissue. The impulse originated from the A-V junctional region goes down the A-V conduction system orthogradely to depolarize the ventricles on the one hand, and goes up the A- $V$ conduction system retrogradely to the atrium on the other. The time for the impulse to pass retrogradely from the pacemaker site to the atrium (PS- $\mathrm{P}^{\prime}$ interval $)$ is equal to $\mathrm{R}-\mathrm{P}^{\prime}$ interval $+\mathrm{HV}$ interval $+\mathrm{C}(\mathrm{C}$ means the conduction time from the subsidiary pacemaker to the His bundle, and, if the escape rhythm is a His bundle rhythm, $\mathrm{C}$ is 0 ). The PS- $\mathrm{P}^{\prime}$ intervals (in msec) calculated in patient 1 were between $[135+\mathrm{C}(95+40+\mathrm{C})]$ and $[220+\mathrm{C}(180+$ $40+\mathrm{C})$ ]. The PI-P' intervals measured were 205 to $320 \mathrm{msec}$.

Certain objections against retrograde conduction were described by Scherf and Cohen. ${ }^{1)}$ They thought that the shortness of some R-P' intervals was astonishing. However, it should be stressed that R-P' intervals do not always represent the PS- $\mathrm{P}^{\prime}$ interval and that the PS-P' interval is equal to R-P' interval plus the time for the impulse to be conducted from the subsidiary pacemaker to the ventricles. Although the normal range of $\mathrm{HV}$ interval has been reported to be either $35-45 \mathrm{msec},{ }^{22)} 25-55 \mathrm{msec},{ }^{23)}$ or $35-55 \mathrm{msec}^{24}$ ) it is possible that $\mathrm{HV}$ intervals of patients with retrograde $\mathrm{V}-\mathrm{A}$ conduction in the presence of complete heart block are abnormally prolonged. Therefore, the PS-P' intervals could be calculated to be longer than the actual R-P' intervals.

(4) Mechanism of retrograde conduction in the presence of complete heart block: Several theories have been proposed to explain retrograde conduction in the presence of complete orthograde A-V block. Cohn and Fraser, ${ }^{25)}$ and Barker ${ }^{26)}$ suggested that a retrograde impulse was produced by mechanical activation of 
the atria or the $\mathrm{A}-\mathrm{V}$ junction above the blocked area. In our patient 1 , this theory could not hold true for the reason described in Discussion (3): retrograde conduction observed during the escape rhythm was not elicited directly by ventricular depolarization. Scherf ${ }^{6}$ ) proposed the possibility that strong electrotonic potentials accompanying the wave of ventricular activity allow a retrograde conduction. This possibility could be excluded in our patient because retrograde conduction during the escape rhythm was elicited by the impulse originated from the subsidiary pacemaker located in the $\mathrm{A}-\mathrm{V}$ junctional tissue, and not from the ventricles (see Discussion 3). Scherf and Shookhoff ${ }^{27}$ ) suggested the existence of parallel pathways in the A-V system, i.e., a functional longitudinal dissociation of the conduction system. Danielopolu and Danuelesco ${ }^{28}$ proposed a separate retrograde pathway of conduction. They thought that the pathway for reversed conduction was located outside the $\mathrm{A}-\mathrm{V}$ conduction system. Adams ${ }^{7}$ postulated that the atria were depolarized in a retrograde fashion most likely through an aberrant pathway. However, if the bypass tract is operating for retrograde conduction in a patient with complete heart block, this tract must show a unidirectional block, i.e., forward block with retrograde conduction. There has been no report of forward block with intact retrograde conduction within a bypass tract in the literature. Wolferth and McMillan ${ }^{29)}$ utilized the concept of decremental conduction as the basis of their theory of $\mathrm{V}-\mathrm{A}$ conduction in the presence of $\mathrm{A}-\mathrm{V}$ block. If a chief barrier is located low in the A-V node, and a decrement started at a higher level (weaker barrier), the orthograde impulse having been subjected to a moderate decrement may be unable to cross the chief barrier. Conversely, the same strength of stimulus starting from the lower level and passing retrogradely may readily cross the initial chief barrier and then pass through the weaker barrier. Watanabe and Dreifus ${ }^{30}$ observed a possible example of unidirectional block within the A-V node, with different degrees of decrement in forward versus retrograde directions, resulting in successful retrograde atrial excitation in the presence of persistent $\mathrm{A}-\mathrm{V}$ conduction failure.

Although the parallel pathways in the A-V system and the bypass tract with unidirectional block could not be excluded, unidirectional block either at the atrial junction with the A-V node, within the $A-V$ node or the uppermost portion of the bundle of His seems to be the most probable mechanism operating in our patients. The evidence demonstrated by Watanabe and Dreifus described above seems to support this conclusion.

\section{Acknowledgement}

The authors would like to thank Prof. Yoshio Watanabe, M.D. for his thoughtful 
criticism of the manuscript. We are grateful to Dr. Kohichi Uno for referring his patient to us.

\section{REFERENGES}

1. Scherf D, Cohen J: The atrioventricular node and selected cardiac arrhythmias, Grunne and Stratton, New York, p 208, 1964

2. Scherf D, Cohen J, Orphanos RP: Retrograde activation of atria in atrioventricular black. Am J Cardiol 13: 219, 1964

3. Winternitz $M$, Langendorf $R$ : Auriculoventricular block with ventriculoauricular response. Report of six cases and critical review of the literature. Am Heart J 27: 301, 1944

4. Louvros N, Costeas F : Retrograde activation of atria in atrioventricular block. Ann Intern Med 116: 778, 1965

5. Fretcher E, Morton P: Atrioventricular dissociation with intact retrograde conduction. Brit Heart J 30: 458, 1968

6. Scherf $\mathrm{D}$ : Retrograde activation in complete heart block. Dis Chest 35: 320,1959

7. Adams CW: Retrograde atrial conduction with complete heart block following implantation of an internal ventricular pacemaker. Dis Chest 43: 544, 1963

8. Gubbay ER, Mora CA: Retrograde conduction and isorhythmic dissociation in heart block. Am Heart J 68: 166, 1964

9. Castillo C, Samet P: Retrograde conduction in complete heart block. Brit Heart J 29: 553, 1967

10. Samet P, Castillo C, Rernstein W: Retrograde P-wave conduction (abstract). Circulation 36 (Suppl): II-229, 1967

11. Goldreyer RN, Bigger JT: Ventriculo-atrial conduction in man. Circulation 41: 935, 1970

12. Tanaka H, Niimura T, Uemura N, Tanaka N, Toyama Y, Atsuchi Y, Nuruki K, Nishi S, Katanazako $\mathrm{H}$, Kanehisa $\mathrm{T}$ : Clinical studies on ventriculoatrial conduction. Jap Circulat J 37: 591, 1973

13. Gupta PK, Haft JI: Retrograde ventriculoatrial conduction in complete heart block. Am J Cardiol 30: 408, 1972

14. Scherlag BJ, Lau SH, Helfant RH, Stein E, Berkowitz W, Damato AN: Catheter technique for recording of His bundle activity in man. Circulation 39: 13, 1969

15. Kistin $\mathrm{AD}$, Landowne $\mathbf{M}$ : Retrograde conduction from premature ventricular contractions, a common occurrence in the human heart. Circulation 3: 738, 1951

16. Narula OS, Scherlag BJ, Samet P, Javier RP: Atrioventricular block: Localization and classification by His bundle recordings. Am J Med 50: 146, 1971

17. Rosen KM: The contribution of His bundle recording to the understanding of cardiac conduction in man. Circulation 43: 961, 1971

18. Damato AN, Lau SH, Bobb GA: Studies on ventriculo-atrial conduction and the reentry phenomenon. Circulation 41: 423, 1970

19. Narula OS: Wolff-Parkinson-White syndrome. A review. Girculation 47:872, 1973

20. Castellanos A, Castillo CA, Agha AS, Tessler M: His bundle electrograms in patients with short P-R intervals, narrow QRS complexes, and paroxysmal tachycardias. Circulation 43: 667,1971

21. Anderson GJ, Grecnspan K, Fisch G: Electrophysiologic studies on Wenckebach structures below the atrioventricular junction. Am J Cardiol 30: 232, 1972

22. Narula OS, Gohen LS, Samet P, Lister JW, Scherlag BJ, Hildner FJ: Localization of A-V conduction defects in man by recording of the His bundle electrogram. Am J Cardiol $25: 228$, 1970

23. Castellanos A, Castillo CA, Agha AS: Contribution of His bundle recording to the understanding of clinical arrhythmias. Am J Cardiol 28: 499, 1971

24. Rosen KM, Rahimtoola SH, Sinno MZ, Gunner RM: Bundle branch and ventricular 
activation in man: A study using catheter recordings of left and right bundle branch potentials. Circulation 43: 193, 1971

25. Cohn AE, Fraser FR: The occurrence of auricular contractions in a case of incomplcte and complete heart block due to stimuli received from the contracting ventricles. Heart 5: 141, 1914

26. Barker PS: The occurrence of auricular beats due to stimulation of the auricles by the contracting ventricles during complete heart block. Am Heart J 1: 349,1926

27. Scherf D, Shookhoff C: Experimentelle Untersuchungen über die "Umkehr-extrasystole". Wien Arch Inn Med 12: 501,1926

28. Danielopolu D, Danuelesco V: Sur la conductibilitè retrograde et sur la phase refractire de l'oreillette. Arch Mal Coeur 15: 365, 1922

29. Wolferth CC, MCMillan TM: Observations on the mechanism of relatively short intervals in ventriculoauricular and auriculoventricular sequential beats during high grade heart block. Am Heart J 4: 521, 1929

30. Watanabe Y, Dreifus LS: Newer concepts in the genesis of cardiac arrhythmias. Am Heart J 76: 114,1968 